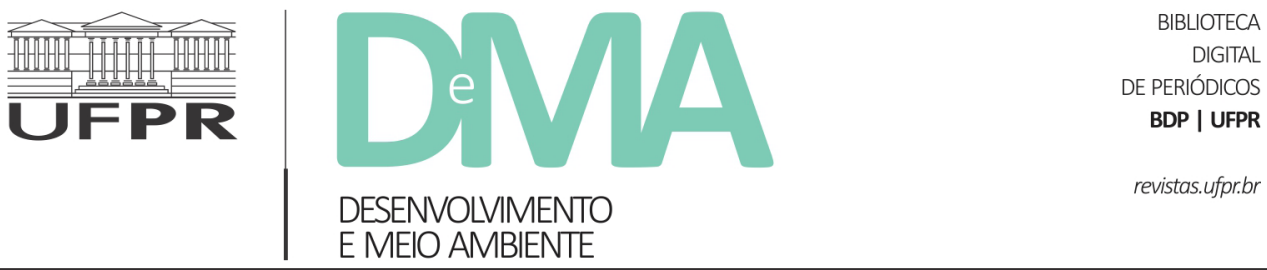

\title{
Veganismo e agroecologia: práticas convergentes para a produção de sistemas alimentares saudáveis e sustentáveis
}

\section{Veganism and agroecology: converging practices for the production of healthy and sustainable food systems}

\author{
Paulo A. NIEDERLE ${ }^{1 *}$, Maycon N. SCHUBERT ${ }^{1}$, Luiza M. TAVARES DA SILVA ${ }^{1}$, Isabela SANDRI ${ }^{1}$, Maiz B. \\ DIAS $^{1}$, Amanda M. GABANA ${ }^{1}$
}

${ }^{1}$ Universidade Federal do Rio Grande do Sul (UFRGS), Porto Alegre, RS, Brasil

*E-mail de contato: pauloniederle@gmail.com

Artigo recebido em 2 de maio de 2020, versão final aceita em 14 de dezembro de 2020, publicado em 20 de setembro de 2021.

\begin{abstract}
RESUMO: $\quad \mathrm{O}$ artigo analisa as convergências entre as práticas alimentares dos adeptos do veganismo e aquelas promovidas pelo movimento agroecológico. Mais especificamente, busca compreender como práticas cotidianas de restaurantes veganos, e seus consumidores, contribuem para a construção de sistemas alimentares saudáveis e sustentáveis nos termos defendidos pelas organizações agroecológicas. Os dados foram coletados entre outubro de 2018 e abril de 2019, período durante o qual observamos in loco as práticas alimentares de dez restaurantes veganos na cidade de Porto Alegre; realizamos entrevistas com chefs, cozinheiros, nutricionistas e proprietários dos restaurantes e aplicamos questionário estruturado a 374 consumidores. Os resultados apontam que, apesar do limitado engajamento político dos restaurantes e consumidores tanto com o movimento vegano quanto com outros movimentos alimentares, a análise das práticas sociais revela convergências entre veganismo e agroecologia.
\end{abstract}

Palavras-chave: práticas alimentares; movimentos sociais; consumo; alimento.

ABSTRACT: This article analyzes the convergences between the food practices of the followers of veganism and those promoted by the agroecology movement. More specifically, it seeks to understand how the daily practices of vegan restaurants and their consumers contribute to the construction of healthy and sustainable food systems in similar terms to those suggested by agroecology organizations. The survey was conducted between October 2018 and April 2019, a period during which we observed the food practices of 10 vegan restaurants in the city of Porto Alegre; conduct interviews with chefs, nutritionists and restaurant owners and applied a structured survey to 374 consumers. Results suggest that, despite limited political engagement of the restaurants and 
consumers both within the vegan movement and other food movements, a closer look at their practices reveals several convergences between veganism and agroecology.

Keywords: food practices; social movements; consumption; food.

\section{Introdução}

Em 2019, o relatório da Comissão Lancet apontou para a conformação de uma "sindemia global" caracterizada pela confluência de três grandes epidemias: mudanças climáticas, obesidade e subnutrição (Swinburn et al., 2019; Willet, et al., 2019). Segundo o documento, a omissão dos governos, o descaso das indústrias e os maus hábitos alimentares da população confluem para um cenário de acelerada destruição dos recursos naturais. Em face disso, demandam iniciativas que ataquem simultaneamente as três faces do problema, evitando que soluções emergenciais para uma epidemia resultem no agravamento de outra - como tem sido historicamente o caso com as políticas de modernização da agricultura, as quais contribuem para reduzir a fome, mas aceleram as mudanças climáticas e as crises de saúde pública (Niederle \& Wesz Junior, 2018). Nesse contexto, ganham relevância as discussões sobre o modo como diferentes práticas de produção e consumo de alimentos podem promover "sistemas alimentares saudáveis e sustentáveis" (SASS) (Blay-Palmer et al., 2019; Lamine et al., 2019).

No linguajar das agências de desenvolvimento os conceitos de "climate-smart agriculture" e " $n u$ trition-sensitive agriculture" têm sido utilizados para destacar a necessidade de adaptar as práticas agrícolas às demandas de uma dieta sustentável
(Burlingame \& Dernini, 2018; Maluf et al., 2015). Uma questão chama particular atenção neste debate, qual seja: a redução da produção e do consumo de carnes. Primeiro, porque a pecuária é apontada como responsável por $14,4 \%$ da emissão de gases de efeito estufa, com destaque para a produção de leite e de carne bovina que, conjuntamente, representam $65 \%$ do total de emissões da pecuária (FAO, 2013) ${ }^{1}$. Segundo, porque o consumo excessivo de carne - que alcança uma média anual de $120 \mathrm{~kg}$ por pessoa no Brasil - é visto como um dos fatores explicativos dos altos índices de doenças não transmissíveis como câncer, diabetes e infartos (Swinburn et al., 2019).

O levantamento realizado pelo Ibope (2018) indica que $63 \%$ dos brasileiros querem reduzir o consumo de carnes e $14 \%$ se consideram vegetarianos - cabe notar que este percentual era de $9 \%$ em 2009 e 8\% em 2012. Esses dados têm levado analistas de mercado a discutir se esta é uma tendência que perdurará e mudará significativamente os hábitos alimentares de grande parte da população, com impactos relevantes nas práticas agrícolas, ou uma moda, que se dissipará mais cedo ou mais tarde. Seja como for, o fato é que existe, atualmente, um apelo crescente pelas dietas que propõem a redução ou exclusão do consumo de carnes. Uma das principais expressões deste fenômeno é o veganismo, movimento que defende não apenas a exclusão do consumo de qualquer produto de origem animal,

\footnotetext{
${ }^{1}$ Estudos recentes apontam que modelos de pecuária sustentável teriam saldo positivo na balança entre emissão e absorção de carbono e, que, portanto, o foco destas críticas deve ser a pecuária convencional (Costa Junior et al., 2019; Matte \& Waquil, 2020).
} 
mas também, em suas versões mais radicais, condena toda e qualquer forma de exploração dos animais não humanos pelos animais humanos (Singer, 1975; Joy, 2013).

No entanto, não é evidente que exista uma confluência entre as críticas e alternativas propostas pelos adeptos do veganismo e aquelas oriundas de outros movimentos que advogam pela construção de SASS. É por isso que, com vistas a compreender as convergências destas pautas e movimentos, este artigo analisa em que medida as práticas dos restaurantes e consumidores veganos vão ao encontro daquelas promovidas pelo movimento agroecológico, o qual, no Brasil, tem capitaneado as discussões sobre a promoção dos SASS. Conformado por organizações de "agricultura alternativa" criadas a partir do final da década de 1970, o movimento agroecológico se tornou o principal vetor das críticas à insustentabilidade do modelo industrial de produção e consumo alimentar, seja em virtude dos seus efeitos ambientais, seja em decorrência dos elevados níveis de insegurança alimentar e nutricional (Brandenburg, 2003; Wezel et al., 2009; Lamine, 2020; Petersen et al., 2020).

A análise não abarca o veganismo como um todo, o qual, como veremos, é um movimento plural e crivado de contradições, ambiguidades e dissidências. Nosso olhar concentra-se nas práticas alimentares dos restaurantes veganos e dos seus consumidores. Entre outubro de 2018 e abril de 2019, observamos in loco dez restaurantes veganos na cidade de Porto Alegre; realizamos dezoito entrevistas com chefs, cozinheiros, nutricionistas e proprietários dos restaurantes; e aplicamos um questionário estruturado a 374 consumidores. A partir disso, foram identificadas as práticas alimentares que interseccionam com a proposta agroecológica, tendo como base para comparação os documentos publicados pela Articulação Nacional de Agroecologia (ANA) ${ }^{2}$ e as demandas das organizações agroecológicas institucionalizadas na Política Nacional de Agroecologia e Produção Orgânica (Pnapo).

$\mathrm{O}$ artigo possui quatro seções além desta introdução. A próxima seção delimita o veganismo e identifica potenciais convergências entre as "práticas veganas" e aquelas defendidas pelo movimento agroecológico. As duas seções subsequentes apresentam os resultados da pesquisa sobre as práticas dos restaurantes e seus consumidores. As considerações finais destacam as principais conclusões e os próximos passos da pesquisa.

\section{O universo das práticas veganas}

$\mathrm{Na}$ literatura acadêmica, o veganismo é comumente representado como um tipo de dieta (Janssen et al., 2016; Aleksandrowicz et al., 2016). Como enfatizam Cole \& Morgan (2011), "quando os veganos estão presentes como participantes da pesquisa, eles geralmente são tratados como um subgrupo de vegetarianos e seu veganismo tende a ser visto como uma forma de ascetismo alimentar envolvendo esforços excepcionais de autotransformação". Nesse caso, acentua-se a exclusão da carne na dieta vegana e deconsidera-se a importância

\footnotetext{
${ }^{2}$ A Articulação Nacional de Agroecologia (ANA) é uma organização que reúne 15 movimentos sociais de abrangência nacional e 23 redes estaduais e regionais de agroecologia, cada qual formada por dezenas de grupos, associações e organizações não governamentais locais. Atualmente, a ANA é a principal entidade de interlocução da sociedade civil brasileira na formulação de ações públicas para a agroecologia.
} 
de outras práticas sociais e, sobretudo, das suas justificações morais associadas ao reconhecimento dos direitos dos animais não-humanos (Cole, 2008; Bruers, 2015).

No Brasil, a Sociedade Vegana, criada em 2010, sustenta uma distinção entre o veganismo como um modo de vida e o vegetarianismo como uma dieta alimentar. No entanto, a confusão é generalizada, e mesmo os membros mais ativos dos movimentos veganos ainda gastam muito tempo tentando identificar as fronteiras entre a dieta e a ética. Esta disputa é fundamental, haja vista que o enquadramento semântico (construção de significado) é um trabalho essencial para definir as configurações, as fronteiras e as hierarquias no interior de qualquer movimento social (Fligstein \& McAdam, 2012). Com efeito, os resultados desta disputa não apenas demarcam as diferenças entre o veganismo e outros movimentos, mas definem as posições internas de diferentes atores (Pereira \& Silva, 2017).

Existem pelo menos duas grandes vertentes dentre os movimentos animalistas, as quais também refletem diferenças em termos de dietas alimentares, os "bem-estaristas" e os "abolicionistas". Os bem-estaristas são aqueles que aceitam a exploração, mas estão sempre em busca de melhorias nas condições de vida dos animais (especialmente daqueles em criatórios), sob o preceito das chamadas cinco liberdades: livres do medo e estresse, livres da dor e da doença, livres da fome e da sede, livres para expressar seu comportamento e livres de desconforto (Broom \& Molento, 2004). Este grupo está geralmente ligado às posições de zootecnistas, veterinários e agrônomos que trabalham com práticas relacionadas ao bem-estar animal em sistemas de pecuária sustentável. Para eles, os animais são seres que merecem atenção, com os quais os humanos desenvolvem empatia, mas não são dotados de direitos.

Já os abolicionistas podem ser divididos em dois subgrupos. Por um lado, os abolicionistas pragmáticos defendem que a maioria das pessoas deve fazer tudo o que for possível para minimizar o sofrimento animal, com o objetivo final de atingir a libertação plena dos animais não-humanos. Esta abordagem está fortemente conectada ao conceito de senciência - capacidade dos seres vivos de sentir dor e prazer - e foi desenvolvida no livro Libertação Animal, de Peter Singer (1975), um dos principais expoentes do movimento. Por outro lado, a segunda corrente abolicionista articula-se em torno de um discurso anti-especista radical. Alinhada aos preceitos éticos e morais descritos por Tom Regan, autor de Jaulas Vazias (2004), esta vertente argumenta que a exploração dos animais se assemelha ao racismo e ao sexismo e que, portanto, deve ser combatida na sua essência e sem qualquer tipo de abertura a soluções parciais ou paliativas. Com efeito, condena o "bem-estarismo" na medida em que este remeteria a uma forma de aceitaçãoda exploração (Naconecy, 2009; Trigueiro, 2013).

$\mathrm{O}$ veganismo abolicionista sustenta o argumento de que, mesmo sem capacidade racional, os animais seriam seres dotados de direitos, não podendo ser tratados como objetos ou bens. Os desacordos iniciam, todavia, quando as justificativas para sustentar os direitos dos animais não-humanos entram em contradição com os direitos dos animais humanos, e aqui o tema da "alimentação como direito humano" adentra como uma questão da maior relevância, haja vista que, em uma sociedade que baseia sua dieta no consumo de carne, o direito dos animais não humanos à vida poderia compro- 
meter o direito dos humanos. Enquanto uma parte do movimento vegano está engajada em construir interfaces com outros movimentos com vistas a discutir este dilema moral, outros grupos defendem que o veganismo não pode ser "contaminado" por outras pautas que não aquela dos direitos animais. Esta disputa cria um cenário de enfrentamento com outros movimentos que militam em prol da construção de SASS, em particular com aqueles que defendem a construção de modelos sustentáveis de pecuária como alternativa à produção industrial intensiva de carne.

Com um discurso mais conciliador, que abre espaço inclusive para quem não consegue ou não quer eliminar a proteína animal da dieta, na última década o abolicionismo pragmático ganhou força no interior do movimento vegano. Um dos principais influenciadores deste grupo é Tobias Leenaert, que, em seu livro Como criar um mundo vegano (2017), apoia um conceito segundo o qual ações voltadas para a saúde humana, bem-estar animal e sustentabilidade podem ser incorporadas, no que ele define como "práticas veganas". Esta perspectiva também é seguida por outra ativista e acadêmica, Melanie Joy, que em seu livro Por que amamos cachorros, comemos porcos e vestimos vacas (2013), discute "a ideologia carnista" sob o ponto de vista cognitivista, behaviorista e histórico. Ambos os autores apresentam uma proposta de enquadramento semântico que amplia a abrangência do movimento, permitindo que qualquer pessoa possa desenvolver "práticas veganas".

Essa perspectiva pragmática não reduz a importância da ética. Pelo contrário, ela é um dos fatores de maior relevância na orientação das prá- ticas. No entanto, não limita o veganismo à ética animalista e, com isso, permite analisar as práticas sociais de atores que possuem diferentes níveis de engajamento com o veganismo. Entretanto, ela cria dificuldades para delimitar as fronterias semânticas com outros movimentos como vegetarianismo, flexitarianismo, ovo-lacto-vegetarianismo, pescetarianismo, poloteísmo, crudivorismo, climatarianismo e assim por diante. Os crudívoros, por exemplo, buscam comer alimentos com baixo grau de cocção, o que geralmente implica em uma dieta sem produtos derivados de animais, mas eles não são necessariamente veganos. Por sua vez, amparados por uma forte ideologia ambientalista sustentada pelos discursos científicos e movimentos ecológicos, os climatarianos defendem o "consumo consciente de carbono" e, neste sentido, também tem como um dos principais alvos a redução drástica do consumo de carnes, inclusive recomendando o limite de $65 \mathrm{~g}$ de carne por pessoa por semana, ou $300 \mathrm{~g}$ por mês ${ }^{3}$. Tal perspectiva se aproxima dos chamados flexitarianos, os quais reduzem o consumo de carne sem eliminá-la por completo do cardápio.

Tomando essa perspectiva como referência, nossa pesquisa procurou compreender como as práticas veganas - identificadas como tal pelos próprios atores sociais - articulam-se à construção de SASS e, mais especificamente, às propostas do movimento agroecológico. Para tanto, inicialmente identificamos as práticas alimentares mais recorrentes nas publicações da Articulação Nacional de Agroecologia, com particular atenção para o documento recém-publicado intitulado "Redes de agroecologia para o desenvolvimento dos territórios: aprendizados do Programa Ecoforte", o qual apresenta a

${ }^{3}$ Neste sentido, ver https://www.lessmeatlessheat.org/climatarian-diet/ 
síntese de um processo nacional de sistematização participativa de práticas agroecológicas de 25 redes territoriais de agroecologia (ANA, 2019). Complementarmente, foram analisadas as diretrizes orientadoras da Política Nacional de Agroecologia e Produção Orgânica (Pnapo), as quais expressam as demandas de diferentes organizações agroecológicas em termos de políticas públicas (Brasil, 2012). Além disso, a análise da "agenda agroecológica" também se beneficiou dos resultados de pesquisas anteriores conduzidas pelos autores (Niederle \& Schubert, 2020; Niederle et al., 2019; 2020).

A catalogação destas informações por meio de análise de conteúdo permitiu identificar quatro grandes arranjos de práticas alimentares: (a) promoção da soberania e segurança alimentar e nutricional por meio da oferta de produtos orgânicos e isentos de contaminantes que colocam em risco a saúde; (b) promoção do uso sustentável dos recursos naturais e conservação dos ecossistemas com a adoção de métodos que reduzam resíduos poluentes e a dependência de insumos externos; (c) promoção de sistemas alimentares justos e sustentáveis que priorizem o apoio às agriculturas de base familiar e (d) valorização dos produtos da sociobiodiversidade. A partir desses arranjos, foram estruturados os guias para realização das observações nos restaurantes veganos, os roteiros para as entrevistas com os chefs, nutricionistas, proprietários e administradores destes restaurantes, bem como as perguntas do questionário estruturado entregue aos consumidores. As práticas apresentadas a seguir são aquelas que apresentaram com maior recorrência na pesquisa.

\section{Muito além da carne: as práticas alimentares dos restaurantes veganos}

Para a seleção dos restaurantes, foram excluídos os estabelecimentos que servem lanches prontos $\mathrm{e}$, assim, identificamos dez restaurantes veganos em Porto Alegre, todos os quais aceitaram participar da pesquisa. O restaurante mais antigo foi inaugurado em 2006, mas a maioria foi aberta apenas nos últimos três anos e nem todos começaram veganos: três fizeram essa "conversão" depois de algum tempo, por princípio ético e/ou por oportunidade de mercado. Atualmente, cinco são administrados por proprietários veganos. No entanto, dentre os outros cinco, dois são geridos por coletivos formados por indivíduos veganos, não-veganos e "em transição" - identidade adotada por alguns membros que possuem uma dieta vegetariana e pretendem se tornar veganos. Por sua vez, a "identidade" dos restaurantes foi definida pelos autores a partir da interpretação e categorização de informações aferidas nas entrevistas e nos sites dos restaurantes sobre o modo como eles se apresentam para o público consumidor; ou seja, não são expressões identitárias autoatribuídas (Tabela 1).

A maioria dos restaurantes se concentra na região central de Porto Alegre, em bairros de classe média e classe alta, como Bonfim, Petrópolis e Rio Branco. No entanto, os preços são muito variáveis, o que, como veremos à frente, atrai consumidores de diferentes faixas de renda. As opções mais caras (acima de $\mathrm{R} \$ 30,00$ ) foram encontradas em restaurantes que não iniciaram com foco no veganismo, mas que o incorporaram como uma identidade secundária, haja vista que ainda privilegiam outras dietas, ou porque visualizaram ali um novo nicho de 
consumo. Por sua vez, os restaurantes com preços mais reduzidos - incluindo um caso (B) em que o consumidor escolhe o quanto pagar - são aqueles que já iniciaram a partir do engajamento prévio dos proprietários com algum grupo ou organização do movimento vegano.

Uma primeira aproximação analítica aos significados que orientam as práticas dos proprietários, chefs, nutricionistas e administradores dos restaurantes nos levou à seguinte tipificação dos restaurantes: a) dois (B e C) identificam-se como "antiespecistas", lutam pela libertação dos animais e contra o sexismo e o racismo, o que os colocam próximos ao abolicionismo mais radical; b) dois (D e J) são "animalistas", advogam pela libertação dos animais, mas sem conectar isso às pautas de libertação humana, o que caracterizaria um abolicionismo pragmático; c) dois (E e F) assumem uma identidade "eco-gourmet", haja vista que uma estética ecológica sobressai frente às questões éticas e políticas; d) um (A) adota um "ecologismo" politicamente engajado, destacando sobretudo o vínculo entre a alimentação e as pautas ambientalistas; e) dois ( $\mathrm{H}$ e I) são voltados para a filosofia "crudívora", cujo foco são os nutrientes que a comida fornece e o melhor aproveitamento destes pelo corpo; f) por fim, um $(\mathrm{G})$ foi classificado como "etno-saudável", pois volta-se mais à oferta de comida étnica e saudável do que à ética animalista ou às questões ambientais.

No entanto, logo percebemos que esta classificação identitária dos restaurantes ocultava o fato de que muitas práticas sociais são comuns a todos eles. Em função disso, o foco da pesquisa buscou caracterizar os diferentes arranjos de fazeres e dizeres. De acordo com Schatzki (2002), as práticas sociais são compostas por todos os fazeres - plantar, colher, comprar, distribuir, comer, embalar etc - e dizeres - declarações que manipulam significados sobre como as práticas devem ser feitas - que organizam relações, posições e significados não apenas para os humanos (identidades sociais), mas para todas as entidades, incluindo os animais não humanos e os artefatos materiais. Na medida em que as práticas são inseparáveis dos seus significados, esses fazeres

TABELA 1 - Características gerais dos restaurantes veganos de Porto Alegre em 2019.

\begin{tabular}{|c|c|c|c|c|c|c|c|c|c|c|}
\hline & $\mathbf{A}$ & B & $\mathbf{C}$ & D & $\mathbf{E}$ & $\mathbf{F}$ & $\mathbf{G}$ & $\mathbf{H}$ & I & $\mathbf{J}$ \\
\hline Foco inicial & Vegano & Vegano & Vegano & Vegano & Saudável & Saudável & Indiana & Saudável & Crudívora & Vegano \\
\hline $\begin{array}{l}\text { Conversão } \\
\text { veganismo }\end{array}$ & - & - & - & - & 2014 & 2015 & 2008 & 2015 & - & - \\
\hline $\begin{array}{l}\text { Tipo de } \\
\text { prato }\end{array}$ & $\begin{array}{l}\text { Prato } \\
\text { do dia }\end{array}$ & $\begin{array}{l}\text { Prato } \\
\text { do dia }\end{array}$ & $\begin{array}{c}\text { Buffet } \\
\text { livre }\end{array}$ & $\begin{array}{l}\text { Prato } \\
\text { do dia }\end{array}$ & $\begin{array}{l}\text { Prato do } \\
\text { dia }\end{array}$ & Buffet livre & Prato do dia & Buffet livre & Buffet livre & $\begin{array}{l}\text { Buffet } \\
\text { livre }\end{array}$ \\
\hline Preço (R\$) & 25,00 & Livre & 22,00 & 18,90 & 39,90 & 20,00 & 39,90 & 39,00 & 35,00 & 29,90 \\
\hline $\begin{array}{l}\text { Proprietári- } \\
\text { os veganos }\end{array}$ & Sim & $\begin{array}{l}\text { Coleti- } \\
\text { vos }\end{array}$ & $\begin{array}{l}\text { Coleti- } \\
\text { vos }\end{array}$ & Sim & Sim & Não & Sim & Não & Não & Sim \\
\hline $\begin{array}{l}\text { Identidade } \\
\text { principal }\end{array}$ & $\begin{array}{l}\text { Ecolo- } \\
\text { gista }\end{array}$ & $\begin{array}{l}\text { Anties } \\
\text {-pecista }\end{array}$ & $\begin{array}{l}\text { Anties } \\
\text {-pecista }\end{array}$ & $\begin{array}{l}\text { Ani- } \\
\text { malista }\end{array}$ & $\begin{array}{c}\text { Eco } \\
\text { Gourmet }\end{array}$ & $\begin{array}{c}\text { Eco } \\
\text {-Gourmet }\end{array}$ & $\begin{array}{c}\text { Etno- } \\
\text { saudável }\end{array}$ & Crudívora & Crudívora & $\begin{array}{c}\text { Ani- } \\
\text { ma-lists }\end{array}$ \\
\hline
\end{tabular}

FONTE: Elaborado pelos autores (2019). 
e dizeres devem ser interpretados para se tornarem inteligíveis, o que implica um esforço de triangulação metodológica: observação dos atores em ação e entrevistas para compreender os significados que eles atribuem ao que fazem (Schubert, 2017).

A Tabela 2 apresenta as práticas alimentares desenvolvidas pelos restaurantes mais estreitamente identificadas com as propostas do movimento agroecológico. A intensidade com que cada prática está presente em cada restaurante foi classificada em uma escala que vai da ausência completa (-) ao forte envolvimento $(++++)$. Inicialmente, classificamos o uso de alimentos autoproduzidos (I), a porcentagem de alimentos comprados diretamente de agricultores (II) e o uso de produtos orgânicos (V) com base nas estimativas fornecidas pelos proprietários e gerentes dos restaurantes: $0(-) ; 1 \% \leq 15 \%(+) ; 16 \% \leq$
$50 \%(++) ; 51 \% \leq 75 \%(+++) ; \geq 76 \%(++++)$. Em seguida, comparamos os restaurantes em termos da adoção de práticas ecológicas (III), formas de sociabilidade e interação não mercantil com fornecedores (IV), e a associação dos alimentos a dimensões culturais e sagradas (VIII). Finalmente, definimos o acesso aos alimentos (VI) de maneira inversamente proporcional ao preço. Dentre o conjunto dos restaurantes analisados, as práticas que mais se destacam pela sua recorrência são, respectivamente, VII, VIII, II, III e V (Tabela 2).

O boicote a alimentos ultraprocessados, transgênicos e com alto teor de sódio, açúcar e gordura (VII) - expressão importante da promoção da soberania e segurança alimentar e nutricional - foi um dos aspectos que mais chamou a atenção, seja porque se trata de uma prática fortemente associada

TABELA 2 - Práticas alimentares dos restaurantes veganos de Porto Alegre em 2018.

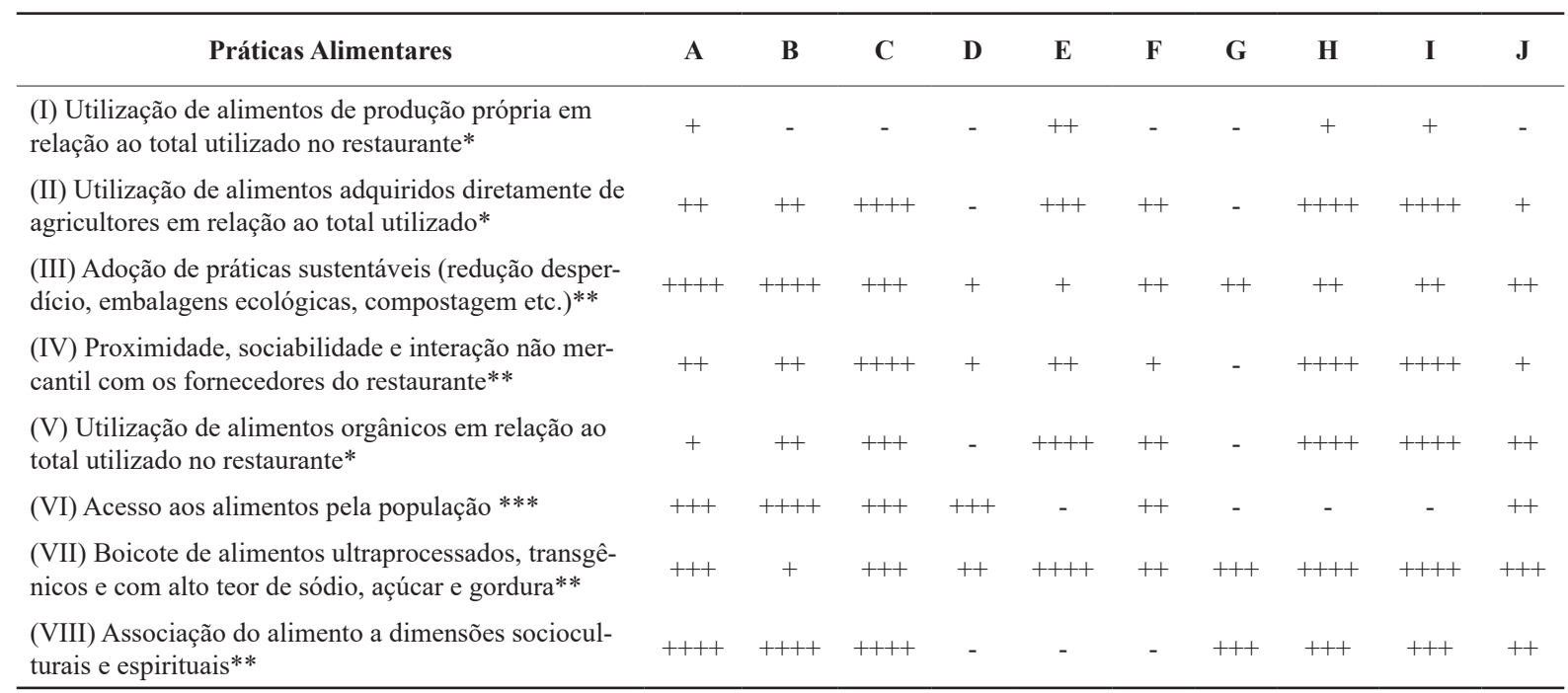

FONTE: Elaborados pelos autores.

Legenda: (*) Classificado com base nas estimativas fornecidas pelos restaurantes: $0(-) ; 1 \% \leq 15 \%(+) ; 16 \% \leq 50 \%(++) ; 51 \% \leq 75 \%(+++) ; \geq$ $76 \%(++++) .(* *)$ Classificado de maneira comparativa entre os restaurantes. $(* * *)$ Classificado de maneira inversamente proporcional ao preço. 
ao discurso agroecológico ${ }^{4}$, seja porque contradiz o estereótipo de que os veganos estariam deixando de comer carne para se tornarem reféns de alimentos ultraprocessados que poderiam, em tese, ser ainda mais danosos à saúde e ao ambiente. Essa preocupação é expressa, por exemplo, por Morris \& Kirwan (2006), os quais sugerem que, similarmente ao que ocorreu com a "convencionalização dos orgânicos", a "dieta vegana" já teria sido apropriada pela indústria alimentar. De fato, nossas entrevistas apontaram uma preocupação nesta direção, inclusive por parte da nutricionista e proprietária dos restaurantes crudívoros ( $\mathrm{H} \mathrm{e} \mathrm{I}$ ) para quem o consumo excessivo de produtos industrializados como refrigerantes e biscoitos produz mais resíduos e é mais prejudicial à saúde do que o consumo de carne. No entanto, na maioria dos restaurantes as duas preocupações caminham juntas, o que permite corroborar a percepção de Stănescu (2010, p. 27) sobre o "falso dilema" de que "é impossível preocupar-se ao mesmo tempo com o bem-estar animal, o meio ambiente e as questões mais amplas de política e justiça alimentar".

Segundo Stănescu (2010), o discurso contra o monocultivo de grãos frequentemente se converte em ataques irracionais aos vegetarianos e veganos, como se as duas únicas opções possíveis fossem comer carne ou produtos industriais ultraprocessados. A soja se tornou o "grão da discórdia" (Menasche, 2005) também neste debate. Dentre os restaurantes analisados, somente dois (D e F) utilizam-no em seus pratos e, segundo seus proprietários, que são críticos à substituição da carne pela proteína de soja, isso se deve apenas à demanda dos consumidores. Em outros quatro restaurantes (E, G, H e I), a soja é utilizada apenas no tofu, e desde que seja certificada não-transgênica. Os demais fazem questão de excluí-la, seja porque consideram seu consumo inadequado a uma dieta saudável, seja porque são críticos ao que o grão representa no moderno sistema agroalimentar. Não obstante, a soja é apenas um exemplo de um conjunto mais amplo de práticas de boicote a este tipo de alimento. Outros dois exemplos são o milho e a ervilha, que geralmente são excluídos dos pratos porque os restaurantes somente têm acesso aos produtos enlatados ou transgênicos. Em alguma medida, este resultado corrobora à conclusão de Stănescu (2010), segundo a qual a maioria dos adeptos do veganismo são mais conscientes dos perigos da comida e da agricultura industrializadas do que a população em geral, e isso porque teriam desenvolvido uma autocrítica mais profunda em relação aos impactos de suas práticas de consumo.

A associação do alimento às dimensões socioculturais, afetivas e espirituais (VIII), a qual está no âmago de uma compreensão da agroecologia como uma filosofia de vida e não apenas como um processo técnico-produtivo (Silva, 2017), também é uma das práticas mais recorrentes entre os restaurantes veganos. O restaurante A, por exemplo, altera regularmente seu cardápio para oferecer pratos típicos de diferentes países, promovendo o reconhecimento dos recursos da sociobiodiversidade, além de "tratar" os alimentos com terapia musical

\footnotetext{
${ }^{4}$ Sobre a centralidade desse debate para o movimento agroecológico, sugerimos ler a manifestação publicada dia 05 de outubro de 2020 pela Associação Brasileira de Agroecologia em reação à Nota Técnica 42/2020 do Ministério da Agricultura, Pecuária e Abastecimento (MAPA). Publicada no dia 15 de setembro de 2020, esta nota questionou as recomendações do Guia Alimentar para a População Brasileira com relação ao perigo do consumo de alimentos ultraprocessados. Disponível em: https://aba-agroecologia.org.br/em-defesa-do-guia-alimentar-para-a-populacao-brasileira/. Acesso em 02/11/2020.
} 
antes de prepará-los. Outro exemplo é a exclusão do cardápio do restaurante $\mathrm{G}$ de alimentos como alho e cebola, os quais, para determinadas culturas, são considerados medicinais e, portanto, não devem ser consumidos diariamente. Destaca-se ainda o modo como os restaurantes $\mathrm{B}$ e $\mathrm{C}$ associam seus pratos a expressões culturais do punk e do anarquismo. Finalmente, a origem dos restaurantes $\mathrm{H}$ e I esteve associada a princípios da religião espiritista adotada pela proprietária.

Uma das práticas mais importantes para os movimentos da agroecologia é a reconexão dos produtores com os consumidores por meio do desenvolvimento de mercados locais e circuitos curtos (Darolt, 2013; Niederle \& Wesz Junior, 2018). Vários restaurantes (C, E, H, I) incluem em seus repertórios de práticas a compra direta de agricultores familiares em quantidades substanciais. Os canais mais utilizados são as feiras livres, onde os restaurantes escolhem os alimentos, mas também é recorrente a entrega nos restaurantes pelos agricultores. Seja qual for o canal, os restaurantes que compram diretamente dos agricultores geralmente adequam seus menus à sazonalidade dos alimentos, algo que não ocorre dentre aqueles que utilizam principalmente os supermercados e as centrais de abastecimento. Ademais, cabe destacar o investimento feito pelo restaurante I para instalar uma banca em frente ao estabelecimento, onde um agricultor familiar, fornecedor regular do restaurante, comercializa seus produtos orgânicos para $o$ público em geral.

A aquisição de alimentos diretamente dos agricultores (II) está associada a outra prática relevante para os objetivos desta pesquisa, qual seja, o uso de alimentos frescos e orgânicos, os quais também são considerados mais nutritivos pelos chefs e nutricionistas entrevistados. No entanto, nenhum restaurante demanda qualquer tipo de certificação, e nem identifica seus pratos como orgânicos, mesmo quando o cardápio chega a ser composto com quase $90 \%$ de alimentos orgânicos. Segundo os administradores dos restaurantes mais engajados no uso deste tipo de alimento, os consumidores menos habituais identificam esse vínculo pelas referências que encontram nos materiais de divulgação ou nas paredes dos restaurantes, nos quais é recorrente o uso de expressões como "ecológico" e "natural". Já os consumidores regulares acessam estas informações conversando com atendentes, cozinheiros e chefs, muitos dos quais fazem questão de ir até as mesas e falar, dentre outras coisas, sobre a origem dos produtos utilizados.

A maioria dos restaurantes alega duas dificuldades principais para ampliar o percentual de alimentos orgânicos nos cardápios. A primeira, também muito presente nas discussões das organizações agroecológicas, tem a ver com a logística de distribuição (Perez-Cassarino \& Meireles, 2018). A maioria dos restaurantes não tem mão de obra disponível para se deslocar diariamente até os agricultores ou às feiras. Por sua vez, os fornecedores que entregam diretamente nos restaurantes não possuem a variedade demandada para os cardápios. Em virtude disso, a compra em supermercados ou centrais atacadistas acaba sendo mais conveniente. Já a segunda dificuldade está associada ao preço dos alimentos orgânicos. Como o preço é variável entre os diferentes canais de comercialização, somente os produtos orgânicos comprados diretamente dos agricultores (mais baratos) são viáveis economicamente para os restaurantes.

A compra direta e o uso de orgânicos são práticas que se retroalimentam e que, em algum grau, 
dependem uma da outra para existir. Com efeito, se não fosse com o intuito de comprar alimentos orgânicos, os restaurantes não fariam esforço para comprar diretamente dos agricultores. Soma-se a isso outra prática que, embora não seja tão generalizada, se mostrou expressiva em três restaurantes (C, H e I), qual seja a construção de vínculos de proximidade, sociabilidade e interação não mercantil com os agricultores fornecedores (IV). Os responsáveis por estes restaurantes já convidaram os agricultores para o almoço, foram visitá-los em suas propriedades rurais, indicaram seus produtos para os consumidores, organizaram grupos de consumidores para ir até as propriedades rurais ou promoveram "lives" em redes sociais virtuais para discutir com eles temas sobre agricultura e alimentação. Assim, além da inclusão econômica, estes restaurantes potencializam um processo de reconhecimento social que é fundamental para agregar "valores" aos alimentos e que tem sido um dos fatores diferenciais das relações econômicas solidárias do movimento agroecológico (Niederle, 2014).

Embora seja uma prática com um número crescente de adeptos no universo da gastronomia sustentável, e considerada estratégica para o movimento agroecológico do ponto de vista da segurança e soberania alimentar dos agricultores e comunidades rurais, o cultivo dos próprios alimentos (I) é uma prática pouco difundida entre os restaurantes veganos de Porto Alegre. Somente um restaurante (E) se destacou, na medida em que cerca de 50\% de toda matéria prima provém de um sítio mantido pela família do proprietário do restaurante. Segundo informado pelo proprietário, o objetivo desta produção própria é precisamente garantir o acesso a alimentos orgânicos, locais e com baixo custo. No entanto, este exemplo apenas chama a atenção para o fato de que o único restaurante que aposta nesta prática é aquele em que as condições para a produção agrícola já eram previamente existentes à própria criação do restaurante. Ou seja, em nenhum caso nota-se um movimento dos restaurantes em direção à criação das condições para a produção própria de alimentos.

Outra prática relevante no universo de restaurantes investigados é a adoção de práticas sustentáveis (III), tais como a exclusão ou redução do uso de sacolas plásticas; o tratamento de resíduos orgânicos em composteiras; e o uso de papel reciclável nas embalagens - como argumenta um proprietários de um dos restaurantes: "o foco maior é no meio ambiente; as entregas dos hambúrgueres são feitas à noite e são entregues em uma caixa de papelão com dados sobre o uso da embalagem, consumo de água, uso de grãos para produção animal etc". Outro aspecto a destacar neste sentido é a adoção de práticas para redução do desperdício e das perdas alimentares, com destaque para iniciativas de diminuição das porções servidas, sem estabelecer limites ao consumo. Esta ação é interessante porque, embora a justificativa principal seja de ordem ecológica, ela também contribui para a segurança alimentar e nutricional. A predominância do sistema de "prato do dia" nos restaurantes veganos caminha na contramão da tendência de consumo na maioria dos restaurantes brasileiros, onde se disseminou o "buffet livre". Além de reduzir o desperdício alimentar, esta prática contribui na redução de problemas de saúde associados ao consumo excessivo de alimentos incentivado pela ideia de comer o máximo possível pelo mesmo preço.

Finalmente, a preocupação com a ampliação do acesso aos alimentos foi associada aos preços dos pratos ofertados. Assim como ocorre com os 
alimentos orgânicos, em geral tem-se a ideia de que a dieta vegana é cara. Como demonstramos acima (Tabela 1), dentre os dez restaurantes pesquisados, cinco praticam preços acima ou próximos a $\mathrm{R} \$$ 30,00 , valor superior ao preço médio dos buffets livres encontrados nos mesmos bairros. No entanto, os demais possuem preços similares ou menores do que os buffets, inclusive com um restaurante que adota preço-livre. Esta situação é muito similar àquela encontrada nos restaurantes que ofertam alimentação ecológica e, do mesmo modo, o principal problema em termos de acesso não parece ser primeiramente o preço praticado, mas o fato de que estas iniciativas ainda não se disseminaram para as periferias das grandes cidades. Como destacou uma das proprietárias, “o veganismo está começando a entrar nas classes $\mathrm{C}$ e D, em razão das informações e da formação, e nem tanto em razão dos preços". Nesse sentido, pode-se dizer que os movimentos vegano e agroecológico compartilham de um desafio similar de aproximar-se dos contextos sociais onde reside ou trabalha a maior parte da população de baixa renda.

\section{As práticas alimentares dos consumidores}

Nesta seção analisamos as práticas alimentares de 374 consumidores que responderam a um questionário entregue quando ingressavam para almoçar nos restaurantes pesquisados. Para coletar estes dados, os restaurantes nos solicitaram que isso fosse feito por meio da entrega aos consumidores de um questionário para autopreenchimento durante ou após o almoço. Para incluir públicos diferentes, este procedimento foi realizado em um dia da semana $\mathrm{e}$ outro no fim de semana.

Em média, apenas 16\% dos respondentes se consideraram veganos (Tabela 3$)^{5}$. No entanto, essa proporção é muito variável de um restaurante para outro, atingindo $36 \%$ e $50 \%$ nos restaurantes $\mathrm{J}$ e A, respectivamente, e apenas $5 \%$ no restaurante $\mathrm{E}$. Cabe destacar, todavia, que $42 \%$ de todos os consumidores afirmaram não ter consumido carne no último mês, e 39\% no último ano. Isso demonstra que há um grande número de vegetarianos nesta amostra. Além disso, entrevistados também apon-

TABELA3 - Consumidores por dia, amostra e número de consumidores veganos autoidentificados.

\begin{tabular}{|c|c|c|c|c|c|c|c|c|c|c|c|}
\hline & $\mathbf{A}$ & B & $\mathbf{C}$ & D & $\mathbf{E}$ & $\mathbf{F}$ & G & $\mathbf{H}$ & I & $\mathbf{J}$ & Total \\
\hline Consumidores por dia* & 10 & 60 & 50 & 70 & 45 & 100 & 110 & 70 & 40 & 200 & 755 \\
\hline Amostra & 8 & 42 & 35 & 48 & 40 & 43 & 50 & 42 & 21 & 45 & 374 \\
\hline Autoidentificados veganos (N) & 4 & 6 & 10 & 5 & 2 & 4 & 6 & 5 & 2 & 16 & 60 \\
\hline
\end{tabular}

(*) Número estimado pelos administradores dos restaurantes.

FONTE: Elaborado pelos autores a partir de pesquisa de campo.

\footnotetext{
${ }^{5}$ Se considerarmos o número de consumidores por dia em cada restaurante (Tabela 3 ) e ponderarmos os percentuais de acordo com esta informação, o percentual de consumidores veganos aumentaria para $19 \%$.
} 
taram que alguns consumidores que poderiam estar no grupo dos veganos não se identificam como tal porque têm consciência da dificuldade que é a exclusão completa de todos os produtos de origem animal não apenas da alimentação, mas também no vestuário, nos produtos de higiene pessoal e nos cosméticos. Os significados de "ser vegano" que mais se destacaram para os consumidores dizem respeito a boicotar produtos de origem animal $(18,32 \%)$, não maltratar os animais $(17,78 \%)$, não consumir carne $(16,58 \%)$, e estar engajado na defesa dos animais (12,70\%).

Com relação à caracterização socioeconômica dos consumidores, o nível de instrução se mostrou alto comparativamente à população brasileira em geral, sendo que $40 \%$ possuem pós-graduação e $28 \%$ graduação. No que tange à renda familiar mensal, $27 \%$ estão na faixa acima de doze salários mínimos (S.M.), 17\% entre oito e doze S.M., 33\% entre quatro e oito S.M., 17\% entre dois e quatro S.M., e somente $6 \%$ abaixo de dois S.M. No entanto, este percentual também é muito variável entre os restaurantes de modo que, no restaurante $C$, por exemplo, $21 \%$ dos consumidores têm renda familiar mensal abaixo de dois S.M. Por sua vez, no que diz respeito à faixa etária, os dois principais grupos se concentram entre 25 e 40 anos $(52 \%)$ e entre 15 e $24 \operatorname{anos}(27 \%)$. Finalmente, o que é mais impressionante é que $70 \%$ dos respondentes são mulheres, revelando um perfil de consumidores predominantemente feminino - o que corrobora os resultados de outras pesquisas sobre o vínculo entre veganismo e feminismo (Hamilton, 2016; Doyle, 2016).

No que tange às principais motivações de escolha do restaurante, $32 \%$ dos consumidores referiram a qualidade da comida e $14 \%$ os aspectos morais e políticos. $\mathrm{Na}$ medida em que a qualidade da comida se sobressai como principal motivação, é pertinente pensar que, antes mesmo de assumir uma identidade política, o restaurante preocupa-se em ofertar uma comida boa para comer. Como argumenta Warde (2016, p. 57), "o famoso ditado de Lévi-Strauss é que 'comida é boa para pensar', mas comida também tem que ser boa para comer". Todavia, aqui também há importantes diferenças entre os restaurantes. Por um lado, nos dois restaurantes crudívoros (H e I) os aspectos morais e políticos se mostraram uma preocupação muito pouco relevante na escolha do restaurante pelos consumidores: $2 \%$ e $10 \%$, respectivamente - o que está em consonância com o discurso da sua proprietária, que se diz "vegana por consequência, não por princípio". Por outro lado, nos dois restaurantes antiespecistas (B e C), os aspectos morais e políticos foram referidos como os principais parâmetros para $24 \%$ e $30 \%$ dos consumidores, respectivamente. Também foram nestes restaurantes antiespecistas que identificamos maior engajamento político - analisado a partir da participação pontual em campanhas, da ação em redes sociais, da organização de debates, da participação ativa em ações coletivas e de referências estéticas (frases, expressões, imagens) dispostas nos restaurantes - e não apenas com o movimento vegano, mas também com outras pautas políticas como o anarquismo, o feminismo e a reforma agrária. Apenas os restaurantes A (ecologista) e J (animalista) também apresentaram um nível relativamente elevado de engajamento político. No entanto, enquanto o restaurante A destaca elementos da agroecologia e reforma agrária, no caso do J não há qualquer tipo de engajamento com relação a outras pautas políticas. Ele está fortemente engajado na defesa dos animais, mas, segundo sua proprietária, "tentamos abordar o tema animal por uma ótica positiva... o 
consumidor ajudando os animais, sendo 'fofinhos', e não acusatórios". Na sua interpretação, isto afasta o restaurante da preocupação com outras pautas e movimentos sociais.

A Tabela 4 apresenta o percentual de consumidores que responderam positivamente às questões sobre diferentes formas de engajamento com o veganismo e outros movimentos alimentares. Considerando o conjunto da amostra, apenas $9 \%$ dos 374 consumidores participam de algum movimento social que tem a alimentação como prática estruturante de sua identidade. No entanto, este percentual sobe para $23 \%$ quando consideramos os consumidores que se definem como veganos. A participação destes consumidores também é relativamente mais expressiva nas redes sociais sobre veganismo e, mais amplamente, sobre alimentação, assim como no boicote a empresas que utilizam animais em seus produtos ou para testes. O que é mais interessante, todavia, é o fato de que o engajamento destes consumidores ocorre basicamente por meio da participação em redes sociais virtuais. Foram poucos os que relataram atuação em ações coletivas presenciais, tais como manifestações e protestos de rua, em prol de qualquer causa relacionada com alimentação.

A Tabela 5 detalha o percentual de consumidores engajados em um conjunto de práticas que são recorrentes na pauta dos movimentos agroecológicos. Um dos primeiros resultados a destacar é que $89 \%$ dos consumidores cozinham em suas casas, sendo que cerca de $40 \%$ fazem-no com frequência igual ou superior a quatro vezes por semana. Este percentual é ainda mais expressivo dentre os consumidores veganos: 95\% cozinham em casa, $60 \%$ quatro vezes ou mais por semana. Essa prática é fundamental para a segurança e soberania alimentar e, no caso dos veganos, se torna ainda mais relevante em virtude das restrições que eles ainda encontram na alimentação fora de casa. Apesar da expansão do mercado de produtos veganos, e da explosão dos lanches e das comidas pré-preparadas, segundo os

TABELA 4 - Percentual de consumidores dos restaurantes veganos de Porto Alegre que aderiram às práticas alimentares selecionadas em 2018.

\begin{tabular}{|c|c|c|c|c|c|c|c|c|c|c|c|c|}
\hline $\begin{array}{l}\text { Participa de redes sociais virtuais sobre } \\
\text { veganismo }(\%)\end{array}$ & 33 & 76 & 75 & 38 & 49 & 31 & 25 & 28 & 28 & 21 & 33 & 40 \\
\hline $\begin{array}{l}\text { Participa de redes sociais virtuais sobre } \\
\text { alimentação }(\%)\end{array}$ & 44 & 76 & 88 & 48 & 57 & 35 & 35 & 40 & 36 & 40 & 62 & 49 \\
\hline $\begin{array}{l}\text { Boicota empresas que usam produtos de } \\
\text { origem animal }(\%)\end{array}$ & 14 & 47 & 63 & 60 & 57 & 50 & 33 & 35 & 52 & 38 & 52 & 64 \\
\hline
\end{tabular}

Obs: O percentual de cada restaurante refere-se ao conjunto de consumidores (veganos e não veganos).

FONTE: Elaborados pelos autores a partir de pesquisa de campo. 
entrevistados ainda é difícil garantir alimentação vegana saudável sem recorrer ao preparo dos próprios alimentos. Com efeito, em abril de 2019, nenhum dos restaurantes veganos pesquisados oferecia jantar; todos funcionavam apenas para almoço e, em alguns casos, serviam lanches durante o dia.

A opção por preparar a própria comida é coerente com o fato de que a maioria dos consumidores pesquisados, e em especial os veganos, também evita comer em restaurantes de "fast-food". E mesmo dentre aqueles que frequentam este tipo de estabelecimento, $85 \%$ afirmam que o fazem menos de uma vez por mês. Este resultado corrobora aquele encontrado por Stănescu (2010), a partir do qual o autor sugere que os consumidores veganos são mais conscientes que os demais acerca dos riscos da alimentação ultraprocessada. No mesmo sentido está a informação acerca do elevado percentual de consumidores que comem alimentos orgânicos. E aqui também é importante adentrar nos dados sobre frequência de consumo para apreender as diferenças entre veganos e não veganos. De acordo com os dados da Tabela 5, há uma pequena diferença no percentual de consumidores veganos (93\%) que consomem orgânicos em relação ao percentual (90\%) do total de consumidores da amostra. No entanto, como é possível observar na Figura 1, para quase $60 \%$ dos consumidores veganos esta é uma prática diária, o que somente ocorre com $32,5 \%$ dos consumidores não veganos.

O elevado consumo de orgânicos entre os consumidores veganos é a principal expressão das convergências possíveis do veganismo com a agroecologia. Convergências que se ampliam para outras práticas na medida em que, como já notamos anteriormente, o consumo de orgânicos e a compra dos agricultores familiares parecem se estabelecer como práticas “codependentes” (Schubert, 2017).

TABELA 5 - Percentual de consumidores dos restaurantes veganos de Porto Alegre que aderiram às práticas alimentares selecionadas em 2018.

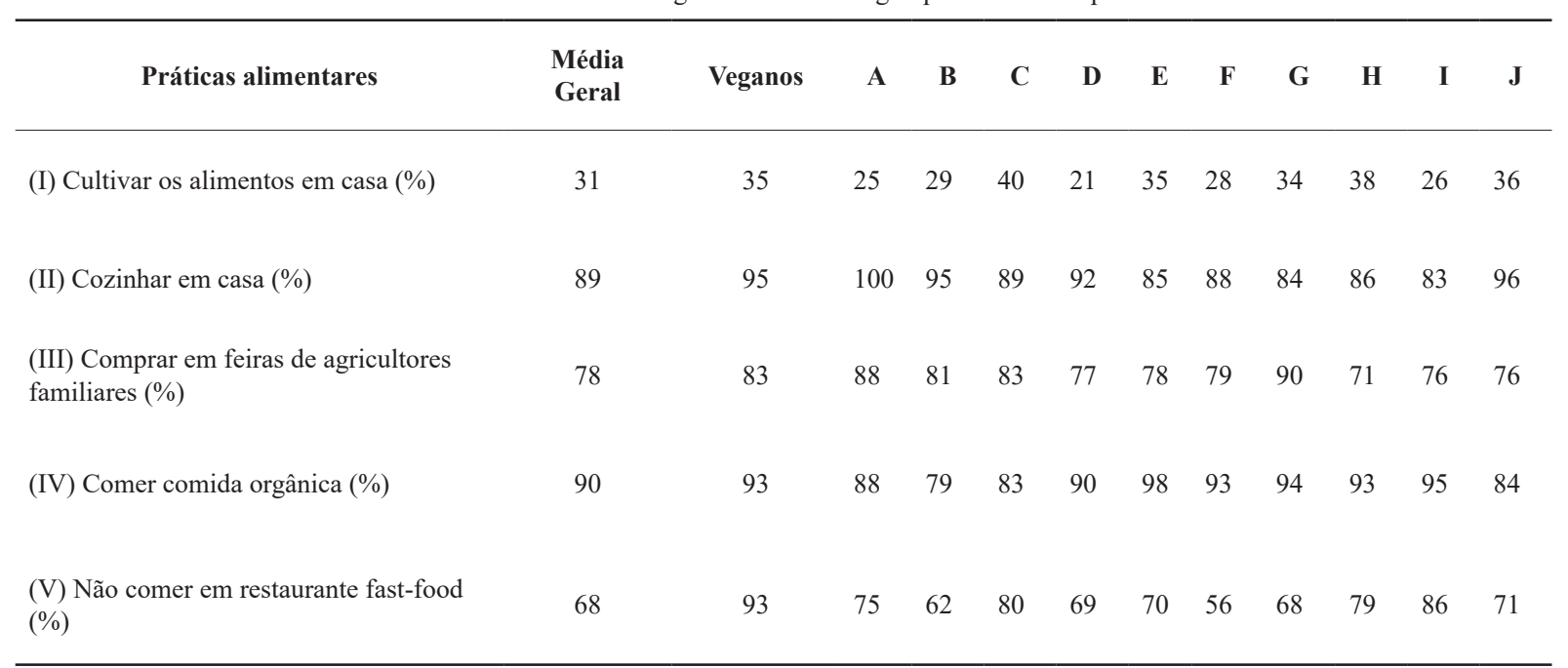

Obs: O percentual de cada restaurante refere-se ao conjunto de consumidores (veganos e não veganos).

FONTE: Elaborados pelos autores. 
Consumidores Veganos (\%)

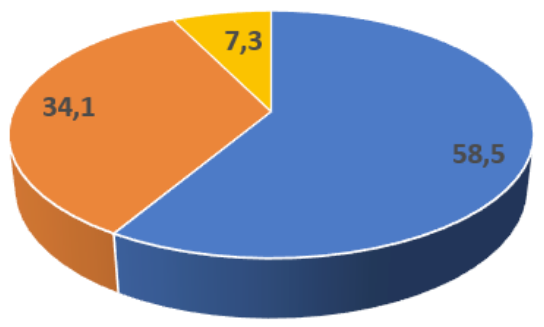

Consumidores Não Veganos (\%)



- Diariamente

- 3-4 vezes por semana

- 1-2 vezes por semana

- Menos de 1 vez por semana

FIGURA 1 - Comparação entre o percentual de consumidores autoidentificados veganos e não veganos dos restaurantes veganos de Porto Alegre conforme frequência de consumo de alimentos orgânicos em 2018.

FONTE: Elaborados pelos autores.

Com efeito, os dados da Tabela 5, acima, também apontam para um elevado percentual de consumidores - acima de $70 \%$ em todos os restaurantes - que frequentam as feiras livres onde os agricultores familiares comercializam seus produtos.

Finalmente, um dos resultados mais importantes refere-se ao fato de que, com relação às práticas alimentares referidas, não existem variações expressivas entre os consumidores dos diferentes restaurantes - pelo menos não na mesma magnitude com que se dá o engajamento político (Tabela 4). O percentual de consumidores que compram nas feiras livres ou que consomem alimentos orgânicos é inclusive maior em alguns restaurantes (D, E, F, $\mathrm{G}, \mathrm{H}$ ) onde notamos pouca preocupação dos seus proprietários e administradores em vincular-se ao movimento vegano ou a outros movimentos alimentares. Esse resultado é importante porque corrobora a ideia de que as práticas veganas e agroecológicas possuem inúmeras convergências e, ao mesmo tempo, são mais generalizáveis do que os movimentos sociais articulados em torno delas. Isto encaminha para uma compreensão pragmatista que, ao invés da sociologia mais habitual que coloca em primeiro plano os atores e suas práticas, privilegiaria as práticas e seus diferentes atores (Cefaï, 2009).

Pesquisas anteriores já revelaram que as feiras agroecológicas são hotspots sociais e políticos para atores de diferentes movimentos alimentares, incluindo veganos e vegetarianos (Lamine, 2020). Nossas próprias pesquisas também demonstram que é recorrente a presença de consumidores veganos e vegetarianos nas organizações do movimento agroecológico (Niederle \& Schubert, 2020). No entanto, eles geralmente estão invisibilizados no interior de um movimento em que, assim como nos 
demais que também têm uma origem predominantemente agrária, prevalece um perfil "carnivorista". O que é mais recente, e ainda pouco explorado pela pesquisa social, é a presença de agricultores ecologistas nas feiras veganas. A partir das observações e entrevistas que realizamos nesses espaços em Porto Alegre, foi possível notar que, apesar de um pouco desconfortáveis no começo, uma vez que eles não são veganos, atualmente estes agricultores já se consideram integrados e apoiadores da causa.

Esses espaços têm sido fundamentais para aproximar ambos os movimentos e, ao mesmo tempo, para questionar a ideia bastante disseminada nos movimentos rurais e agrários de que o veganismo é uma dieta da moda, voltada para uma elite urbana, e já apropriada pelos principais atores da indústria alimentar. Essa crítica que, outrora, já foi dirigida aos adeptos dos alimentos orgânicos, acentua a imagem de que a exclusão da carne não seria acompanhada de uma preocupação nem com a sustentabilidade dos sistemas agrícolas, nem com as diferentes desigualdades sociais (classe, gênero, raça etc.) que o modelo alimentar dominante reproduz. Entretanto, os resultados deste artigo sugerem que esta generalização é abusiva. Embora a maioria dos restaurantes veganos evite um engajamento mais ativo com o veganismo e, mais ainda, com outras pautas morais e políticas, isto está principalmente associado com os desafios comerciais que eles enfrentam para sobreviver na terra do churrasco. Mesmo assim, não se pode desprezar o esforço que alguns deles têm feito para promover não apenas a agroecologia, mas também pautas como a reforma agrária e a agricultura familiar.

\section{Considerações finais}

Este artigo analisou as interfaces entre o veganismo e a pauta defendida pelo movimento agroecológico para a construção de sistemas alimentares saudáveis e sustentáveis. Os resultados apresentados sugerem que os restaurantes veganos e seus consumidores possuem formas individualizadas, virtuais e difusas de engajamento com as questões alimentares. Se por um lado isto os afasta do repertório predominante de ação política do movimento agroecológico que, assim como outros movimentos rurais, tem sua identidade fortemente marcada por episódios de lutas abertas contra o sistema agroalimentar hegemônico; por outro lado, podem-se reconhecer convergências quando focalizamos as formas de resistência cotidiana ancoradas na produção de novas práticas alimentares (Scott, 1987; Ploeg, 2008).

Os dados apresentados apontaram para profícuas interfaces entre as práticas dos consumidores e dos restaurantes veganos com as propostas de reestruturação do sistema agroalimentar sustentadas pelo movimento agroecológico, com destaque para: a defesa da soberania e a segurança alimentar por meio da promoção de uma alimentação saudável (orgânicos, sem ultraprocessados e transgênicos); o uso sustentável dos recursos naturais por meio de práticas ecológicas de tratamentos de resíduos e redução do desperdício alimentar; a promoção de sistemas alimentares justos e sustentáveis que apoiam aos agricultores familiares e, ao mesmo tempo, favorecem o acesso aos alimentos para consumidores de menor renda; e a valorização dos produtos da sociobiodiversidade, incluindo a crítica à expansão dos monocultivos de grãos. 
A principal conclusão do artigo é que, a partir de um olhar mais atento para as práticas alimentares cotidianas, pode-se identificar inúmeras convergências entre veganismo e agroecologia. Embora isso não se expresse com a mesma intensidade nos discursos e no engajamento político e a articulação entre as organizações de ambos os movimentos sociais ainda seja incipiente, é possível perceber que os atores compartilham práticas comuns. Pesquisas futuras demandarão, todavia, um olhar mais atento para as diferenças entre estes dois mundos tão próximos que, frequentemente, parecem separados por um abismo social. A análise das práticas alimentares, tal qual empregada aqui, não nos possibilitou adentrar em outras ordens sociais em que as diferenças podem ser mais marcantes. Este é o caso, por exemplo, das práticas e relações de trabalho, gênero e raça.

No movimento agroecológico já é recorrente a ideia de que "sem feminismo não há agroecologia", lema construído pelo Grupo de Trabalho de Mulheres da Articulação Nacional de Agroecologia. Nossos dados demonstraram o amplo predomínio das mulheres dentre os consumidores pesquisados, sendo que $75 \%$ dos consumidores veganos se identificaram como mulheres. Mesmo assim, nossa pesquisa ainda investigará com mais atenção se os sentidos de feminismo são similares nestes diferentes movimentos. No caso do movimento agroecológico, por exemplo, "o feminismo pelo qual levantamos nossos punhos e bandeiras é o feminismo popular, anticapitalista, antirracista, antiLGBT-fóbico!" (ANA, 2018). Será este o sentido de feminismo sustentado pelos movimentos veganos? Apesar de alguns restaurantes levantarem bandeiras similares a estas, sobretudo aqueles que se associam ao "anarco-veganismo", a difícil aproximação entre veganismo e agroecologia talvez deva a diferenças em outras questões que não aquelas que dizem respeito à alimentação.

Finalmente, no que tange à contribuição teórica do artigo, embora o foco principal não tenha sido produzir nenhum tipo de inovação conceitual, mas interpretar processos sociais contemporâneos de suma relevância (Portilho \& Barbosa, 2016), pode-se afirmar que o artigo se insere no movimento mais amplo de "virada pragmática" das ciências sociais. Assim, sem questionar a validade da agenda de estudos sobre estratégias e repertórios de ação política dos movimentos sociais, que privilegia um olhar para as identidades sociopolíticas, este artigo sugere que as convergências entre diferentes movimentos também podem ser exploradas a partir da compreenssão das suas práticas. Como sugere Cefaï (2009), este olhar para as experiências situadas dos atores pode, inclusive, ser um meio para a construção de compromissos políticos em torno de problemas comuns, aproximando atores que, de outro modo, geralmente são imaginados como portadores de interesses e estratégias incomensuráveis. Além disso, o foco nas práticas pode ser relevante para distinguir a pluralidade de dinâmicas que definem aquilo que equivocadamente vemos como movimentos excessivamente homogêneos. Em outras palavras, ao olhar para as práticas e seus atores, podemos criar meios de diálogo não para os movimentos como um todo, mas para aqueles atores que, inseridos nestes movimentos, transgridem suas fronteiras e geram novas convergências. 


\section{Referências}

Aleksandrowicz, L.; Green, R.; Joy, E.; Smith, P.; Hain, A. The impacts of dietary change on greenhouse gas emissions, land use, water use, and health: a systematic review. PLoSOne11(11): e0165797, 2016. doi: 10.1371/journal. pone. 0165797

ANA - Articulação Nacional de Agroecologia. Sem feminismo não há agroecologia, 2018. Disponível em: < https:// agroecologia.org.br/wp-content/uploads/2018/09/Mulheres_folder-ena_web-1.pdf $>$ Acesso em: mai. 2020.

ANA - Articulação Nacional de Agroecologia. Redes de agroecologia para o desenvolvimento dos territórios: aprendizados do Programa Ecoforte. Rio de Janeiro: ANA, 2019.

Blay-Palmer, A.; Conaré, D.; Meter, K.; Di Battista, A.; Johnston, C. (Orgs.). Sustainable Food System Assessment. London: Routledge, 2019.

Brandenburg, A. Movimento agroecológico: trajetória, contradições e perspectivas. Desenvolvimento e Meio Ambiente, 6, 11-28, 2003. doi: 10.5380/dma.v6i0.22125

Brasil. Decreto $n^{\circ} 7.794$, de 20 de agosto de 2012. Institui a Política Nacional de Agroecologia e Produção Orgânica. Brasil: Governo Federal, 2012.

Broom, D. M.; Molento, C.F.M. Bem estar animal: conceito e questões relacionadas. Review. Archives of veterinary Science, 9, 2, 1-11, 2004. doi: 10.5380/avs.v9i2.4057

Bruers, S. The Core Argument for Veganism. Philosophia, 43(2), 271-290, 2015. doi: 10.1007/s11406-015-9595-5

Burlingame, B.; Dernini, S. (Orgs.). Sustainable Diets, Liking Nutrition and Food Systems. CABI, 2018. doi: $10.1079 / 9781786392848.0000$

Cefaï, D. Como nos mobilizamos? A contribuição de uma abordagem pragmatista para a sociologia da ação coletiva. Dilemas, 2 (4), 11-48, 2009.

Cole, M.; Morgan, K. Vegaphobia: derogatory discourses of veganism and the reproduction of speciesism in UK national newspapers. The British Journal of Sociology, 62(1), 134153, 2011. doi: 10.1111/j.1468-4446.2010.01348.x
Cole, M. Asceticism and hedonism in research discourses of veganism. British Food Journal, 110(7), 706-16, 2008. doi: $10.1108 / 00070700810887176$

Costa Jr., N. B. da; Baldissera, T. C.; Pinto, C. E.; Garagorry, F. C.; Moraes, A.; Carvalho, P. C. de F. Public policies for low carbon emission agriculture foster beef cattle production in southern Brazil. Land Use Policy, 80, 269-279, 2019. doi: 10.1016/j.landusepol.2018.10.014

Darolt, M. R. Circuitos curtos de comercialização de alimentos ecológicos: reconectando produtores e consumidores. In: Niederle, P.; Almeida, L.; Vezzani, F. (Org.). Agroecologia: práticas, mercados e políticas para uma nova agricultura. Curitiba: Kairós, 2013. pp. 139-170.

Doyle, J. Celebrity vegans and the lifestyling of ethical consumption, Environmental Communication, 10(6), 777790, doi: 10.1080/17524032.2016.1205643

FAO - Food and Agriculture Organization f United Nations. Tackling Climate Through Livestock - A global Assessment of Emission and Mitigation Opportunities, 2013. Disponível em: http://www.fao.org/3/a-i3437e.pdf.

Fligstein, N.; McAdam, D. A theory of fields, Oxford: Oxford University Press, 2012.

Hamilton, C. Sex, work, meat: the feminist politics of veganism. Feminist Review, 114(1), 112-129, 2016. doi: 10.1057/s41305-016-0011-1

Ibope - Instituto Brasileiro de Opinião Pública e Estatística. Pesquisa de opinião pública sobre vegetarianismo, 2018. Disponível em: http://www.svb.org.br/images/Documentos/ JOB_0416_VEGETARIANISMO.pdf.

Janssen, M.; Busch, C.; Rödiger, M. H. U. Motives of consumers following a vegan diet and their attitudes towards animal agriculture. Appetite 105, 643-651, 2016. doi: 10.1016/j.appet.2016.06.039

Joy, M. Por que amamos cachorros, comemos porcos e vestimos vacas? São Paulo: Cultrix, 2013.

Lamine, C. Sustainable Agri-Food Systems: case studies in transitions towards sustainability from France and Brazil. New York: Bloomsbury, 2020.

Lamine, C.; Magda, D.; Amiot, M.-J. Crossing Sociologi- 
cal, Ecological, and Nutritional Perspectives on Agrifood Systems Transitions: Towards a Transdisciplinary Territorial Approach. Sustainability, 11(5), 2019. doi: 10.3390/ su11051284

Leenaert, T. How create a vegan world: a pragmatic approach. Latern Books, 2017.

Maluf, R. S.; Burlandy, L.; Santarelli, M.; Schottz, V.; Speranza, J. S. Nutrition-sensitive agriculture and the promotion of food and nutrition sovereignty and security in Brazil. Ciência \& Saúde Coletiva, 20(8), 2303-2312, 2015. doi: 10.1590/1413-81232015208.14032014

Matte, A.; Waquil, P. D. Productive changes in Brazilian Pampa: impacts, vulnerabilities and coping strategies. Nat Hazards, 2020. doi: 10.1007/s11069-020-03934-9

Menasche, R. Os grãos da discórdia e o trabalho da mídia. Opinião Pública (Impresso), 11(1), 169-191, 2005.

Moris, C.; Kirwan, J. Vegetarians: uninvited, uncomfortable or special guests at the table of the alternative food economy? Sociologia Ruralis, 46(3), 192-213,2006. doi: 10.1111/j.1467-9523.2006.00414.x

Naconecy, C. Bem-Estar animal ou Libertação Animal? Uma análise crítica da argumentação anti bem-estarista de Gary Francione. Revista Brasileira de Direito Animal, 4, 5, 235-267, 2009.

Niederle, P. Políticas de valor nos mercados alimentares: movimentos sociais econômicos e a reconstrução das trajetórias sociais dos alimentos agroecológicos. Século XXI - Revista de Ciências Sociais, 4, 162-189, 2014. doi: $10.5902 / 2236672515648$

Niederle, P.; Schubert, M. How does veganism contribute to shape sustainable food systems? Practices, meanings and identities of vegan restaurants in Porto Alegre, Brazil. Journal of Rural Studies, 78, p. 304-313, 2020.

Niederle, P.; Wesz, J. J. V. As novas ordens alimentares. Porto Alegre: UFRGS, 2018.

Niederle, P.; Loconto, A.; Lemeilleur, S.; Dorville, C. Social movements and institutional change in organic food markets: Evidence from participatory guarantee systems in Brazil and France. Journal of Rural Studies, 78, p. 282291, 2020.
Niederle, P.; Sabourin, E.; Schmidt, C. J.; Avila, M.; Petersen, P.; Assis, W. A trajetória brasileira de construção de políticas públicas para a agroecologia. Redes, 24, p. 270-291, 2019.

Pereira, M. M.; Silva, M. K. O dilema do enquadramento interpretativo: o caso das interações entre o movimento dos direitos animais e a grande mídia. Sociedade e Estado, 32, 189-216, 2017.

Perez-Cassarino, J.; Meirelles, L. Rede Ecovida de Agroecologia: origens, princípios e sua concepção de comercialização. In: Perez-Cassarino, J; Triches, R. M; Baccarin, J. G; Teo, C. (Orgs.). Abastecimento Alimentar: Redes Alternativas e Mercados Institucionais. Chapecó: UFFS, 2018. pp. 267-296.

Petersen, P.; Silveira, L.; Fernandes, G.; Almeida, S. Lume: a method for the economic-ecological analysis of agroecosystems. Coventry: CAWR, 2020.

Ploeg, J. D. van der. Camponeses e Impérios Alimentares: lutas por autonomia e sustentabilidade na era da globalização. Porto Alegre: UFRGS, 2008.

Portilho, F.; Barbosa, L. A adesão à "causa" rural e da agricultura familiar por consumidores e seus movimentos organizados. In: Marques, F.; Conterato, M.; Schneider, S. (Orgs.). Construção de mercados e Agricultura Familiar. Porto Alegre: UFRGS, 2016. pp. 251-274.

Regan, T. Jaulas vazias: encarando o desafio dos direitos dos animais. Porto Alegre: Lugano, 2006.

Schatzki, T. The site of the social. Penn State University Press, 2002.

Schubert, M. Comer fora de casa, as práticas e as rotinas alimentares nos contextos da modernidade: Uma leitura comparada entre Brasil, Reino Unido e Espanha. Tese (Doutorado em Sociologia). Porto Alegre: UFRGS: 2017.

Scott, J. Weapons of the weak: everyday forms of peasant resistance. New Haven: Yale University Press, 1987.

Silva, J. de S. Agroecologia e a ética da inovação na agricultura. Redes. 22, 2, 2017. doi: 10.17058/redes.v22i2.9621

Singer, P. Animal Liberation: a new ethics for our treatment of animals. New York: Random House, 1975. 
Stănescu, V. "Green” Eggs and Ham? The myth of sustainable meat and the danger of the local. Journal for Critical Animal Studies, 8(1), 8-32, 2010.

Swinburn, B.; Sacks, G.; Hall, K.; McPherson, K.; Finegood, D.; Moodie, M.; Gortmaker, S. The global obesity pandemic: shaped by global drivers and local environments. Lancet, 378(9793), 804-14,2011. doi: 10.1016/S01406736(11)60813-1

Trigueiro, A. Consumo, ética e natureza: o veganismo e as interfaces de uma política de vida. INTER thesis. 10(1), 237-260, 2013. doi: 10.5007/1807-1384.2013v10n1p237
Warde, A. The Practice of Eating. Cambridge: Polity Press, 2016.

Wezel, A.; Bellon, S.; Doré, T.; Francis, C.; Vallod, D.; David, C. Agroecology as a science, a movement and a practice. A review. Agronomy for Sustainable Development, 29, 503-515, 2009.

Willet, W.; Rockström, J.; Loken, B. et al. Food in the Anthropocene: the EAT-Lancet Commission on healthy diets from sustainable food systems. Lancet, 393 (10170), 447-492. doi: 10.1016/S0140-6736(18)31788-4. 2019 